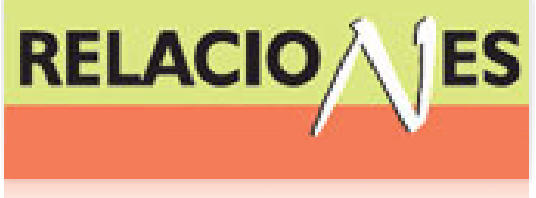

Relaciones. Estudios de historia y sociedad ISSN: 0185-3929

relacion@colmich.edu.mx

El Colegio de Michoacán, A.C

México

Uzeta, Jorge

Mediaciones agraristas en dos municipios guanajuatenses: Atarjea y Xichú

Relaciones. Estudios de historia y sociedad, vol. XXXII, núm. 125, 2011, pp. 53-86

El Colegio de Michoacán, A.C

Zamora, México

Disponible en: http://www.redalyc.org/articulo.oa?id=13718526003

- Cómo citar el artículo

- Número completo

- Más información del artículo

Página de la revista en redalyc.org

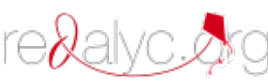

Sistema de Información Científica

Red de Revistas Científicas de América Latina, el Caribe, España y Portugal Proyecto académico sin fines de lucro, desarrollado bajo la iniciativa de acceso abierto 


\section{Mediaciones agraristas en dos municipios guanajuatenses: Atarjea y Xichú}

Jorge Uzeta*

EL COLEGIO DE MICHOACÁN

En este artículo se documenta la ruta política seguida por un par de mediadores agraristas en la Sierra Gorda de Guanajuato. Sus ocupaciones permiten matizar y reforzar elementos de un modelo ampliamente desarrollado en la antropología mexicana: el de los caciques como intermediarios culturales y como constructores regionales de las instituciones estatales de la posrevolución. En el quehacer de estos intermediarios destaca su profunda relación con los peticionarios de tierra y -principal interés en este texto- con los grupos políticos que luchaban por el control de su entidad. Ambos vínculos les permitieron influir profundamente en la historia ejidal de la Sierra, particularmente en la de los municipios enunciados en el título.

(Caciquismo, agrarismo, clientelas, patriarcado)

\section{INTRODUCCIÓN $^{\mathrm{I}}$}

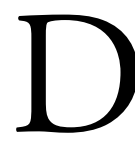

urante el reparto agrario cardenista surgieron en el noreste de Guanajuato algunas vías de comunicación e intermediación política que jugaron un papel muy relevante en la dotación de tierras y en la reconfiguración de un espacio político dominado hasta entonces por grandes propietarios. Salvo algunos pocos trabajos que incluyen las notables memorias de un líder agrarista serrano del que me ocuparé posteriormente, el papel y la

*jorgeuzeta@colmich.edu.mx

${ }^{1}$ En este artículo retomo parcialmente información de varios capítulos incluidos en un trabajo extenso sobre la Sierra Gorda de Guanajuato. 
impronta política que estos personajes tuvieron tanto en la formación de instituciones como en formas específicas de hacer política ha sido minusvalorada y, sobre todo, poco relacionada con las reacciones populares derivadas del avance de las leyes de 1856 en toda la Sierra.

Esas reacciones se expresaron irregularmente y con diversos grados de violencia a lo largo de la segunda mitad del siglo xIx. En Xichú, por ejemplo, se registraron "levantamientos tumultuosos" a propósito de los despojos "de sus tierras y astilleros, por usureros españoles y aún mexicanos pretextando denuncias de deslindes o de baldíos" (González 1904, 388); en San Luis de la Paz las autoridades indígenas de la Misión de Chichimecas, encabezadas por el "mayor" de su "generación", insistieron desde 1886 por la recuperación de sus títulos de propiedad y de su territorio ante las autoridades de gobierno y contra varias haciendas que habían ampliado sus linderos; ${ }^{2}$ en Atarjea, por su parte, existió una constante disputa desde 1872 y hasta las primeras décadas del nuevo siglo contra un empresario alemán, Federico Ernest, que había logrado hacerse con buena parte de los terrenos productivos para su explotación mineral. ${ }^{3}$

Expresiones antiliberales como las anteriores están relacionadas con la defensa de identidades sociales construidas en torno al acceso común de recursos naturales y, destacadamente, con formas locales de poder. Precisamente uno de los intereses permanentes de la antropología en México ha sido documentar y analizar la naturaleza del poder local y los complejos y con frecuencia contradictorios vínculos que establece con la nación. Los protagonistas de tal temática han sido, por una parte, el proceso de centralización e institucionalización del poder político bajo un Estado nacional; por otra, caudillos regionales que lo enfrentan para oponerse y eventualmente desaparecer, o bien líderes locales o comunales que lo encaran para negociar y redefinirse como convenientes agentes del Estado y promotores del desarrollo. Este pacto y los arreglos particulares les permiten recrear

${ }^{2}$ Archivo General del Gobierno del Estado de Guanajuato (AGEG). Fondo gobierno, sección secretaría, serie municipios, lugar San Luis de la Paz, año 1886.

${ }^{3}$ Para el inicio de esta disputa véase AGEG. Fondo gobierno, sección secretaría, serie municipios, lugar Atarjea, año 1871, caja 222, expediente 3. 
su dominio personal dentro de marcos idealmente acotados por leyes nacionales e instituciones federales.

La caracterización de estos personajes, definidos genéricamente como caciques en el sentido de "jefes locales" con grandes habilidades para la adaptación política (Friedrich referido por Joseph 1995, 245), y analíticamente como brokers en su doble acepción de intermediarios culturales e intermediarios políticos (Wolf 1971 [1956]), deriva parcialmente de la perspectiva que argumenta la existencia de estructuras políticas distintas pero coexistentes bajo un mismo sistema (Bartra 1976). En esos términos, De la Peña destacó con buen tino la importancia de la "institucionalización gubernamental del proceso mediador" y -gracias a la propia intermediación- del "surgimiento de núcleos de poder local y regional" comprometidos con el "mantenimiento del orden" (De la Peña 1988, 33, 47).

Pese a que este tipo de enfoques se ven limitados frente a las mediaciones surgidas dentro de una misma estructura política en ámbitos democráticos y urbanos (globalizados incluso), aquellos señalamientos siguen siendo buenas guías para comprender la formación y actualización de poderes locales y nacionales en el campo mexicano al menos durante el siglo pasado. ${ }^{4}$ De hecho la reforma agraria incubada desde la ley carrancista de 1915 puede encuadrarse en esos términos: como un proyecto para fortalecer al Estado llevándolo a "la integración de la nación" (Knight 1995, 84) y, en paralelo, como un programa para fundar ejidos caracterizados por una faz doble y simultánea, la de "un aparato estatal de control político" y la de "un órgano de representación campesina" (Fox y Gordillo citados por Jones 1996, 188). Entre ambas tendencias se encuentra la oscilación o evolución de la que han sido capaces los liderazgos rurales de tipo caciquil, que fomentan "las aspiraciones" campesinas mediante el intercambio de favores para luego "atropellar los intereses" de sus bases de apoyo en la búsqueda de beneficios personales, entre los que se pueden incluir lo mismo la consolidación del corporati-

${ }^{4}$ Trascendiendo la perspectiva estructuralista se ha puesto a discusión si el caciquismo es una forma de interacción dependiente de intereses y relaciones pragmáticas o si más bien se trata de un habitus (Knight 2005, 8; Zárate 2005). El desarrollo de los casos que presentaré contribuye también a este debate. 
vismo posrevolucionario que la construcción de la democracia electoral (Jospeh 1995, 250; Zárate 2005).

Sin embargo, no resulta aventurado sugerir que fue precisamente en la recreación de dominios personales afincados en relaciones informales de parentesco, amistad y lealtad política, en donde tuvo lugar la construcción local de instituciones que paradójicamente han apelado desde entonces a la formalidad e impersonalidad de las leyes. En efecto, se puede comprender el proceso de institucionalización con mayores ventajas si se atiende ese tipo de relaciones y a lo que está en su base: la lógica de intercambio por la cual las comunidades y los grupos campesinos "exigen" o "piden” a través de sus líderes; y los propios funcionarios "dan" o "cumplen la palabra empeñada" actuando como donantes para prestigiarse legitimando su posición (Zárate 2005). La lógica del intercambio y, en consecuencia, la creación de patronazgos y clientelas es una práctica naturalizada, consustancial a la construcción local de las instituciones.

A la perspectiva anterior hay que agregar una posible explicación del por qué de la preminencia masculina en las mediaciones del campo mexicano, pues efectivamente la abrumadora mayoría de las mismas corrió a cargo de hombres. Junto al poder y a la autoridad del hombre sobre la mujer en ámbitos como el sexual, el de estatus social y el familiar, Stern $(1999,42)$ ha identificado que "la autoridad en las células familiares sirve como un modelo metafórico fundamental para la autoridad social más generalizada”. En este sentido, con sustento en la figura del patriarca aunque trascendiéndolo, se construyen imágenes ubicuas de autoridad que en otros niveles y con ciertos matices y contrastes refieren a los hacendados o a los líderes locales y regionales extendiéndose finalmente hasta el gobernador y el presidente de la República. En el centro y norte de Guanajuato, Sepúlveda $(2000,2004,2005)$ ha identificado la formación de "ejidos rancheros", donde los comisariados ejidales devinieron en caciques actualizando el papel autoritario de patrones, rentando tierras, acaparando las contribuciones ejidales y reinterpretando en su beneficio la normatividad agraria. En su perspectiva, los caciques ejidales descollaron gracias a la existencia de una "matriz cultural" en la que la figura del hacendado, con su estampa de 
impunidad, altivez y dominio, era la imagen más acabada. En la base de esta intermediación masculinizada está la imagen familiar del patriarca, ese es el sustento de la matriz cultural identificada por Sepúlveda.

Dentro de muchos ejidos de la Sierra Gorda guanajuatense los elementos matriciales parecen tener una larga consistencia histórica y aún hoy son identificables. En el municipio guanajuatense de Atarjea se puede hablar de una masculinidad severa, de ciertas nociones patriarcales ligadas al dominio y al quehacer político de los hombres en los espacios públicos, de su responsabilidad en el trabajo agrícola, físicamente demandante, y de su manejo de herramientas que incluyen como una extensión las armas y la pericia y el temple implicados en su manejo. Si bien a inicios del siglo xx los hacendados eran referentes físicamente lejanos (por ejemplo, los dueños de la hacienda más cercana, la del Agostadero de Charcas, no vivían en el casco de la propiedad) las presencias más inmediatas eran los administradores encargados de cobrar la renta de tierras y pastos, y el empresario minero alemán seńalado al inicio, con amplias propiedades en la zona.

En algunos documentos en los que los extensionistas del gobierno recapitulaban la historia del lugar para argumentar a favor del reparto de tierras, estos administradores aparecen con una enorme capacidad de control sobre la tierra y sobre todo el abanico productivo de las familias rurales (que incluía granos, artesanías, recolección y ganadería). Pese a las reservas con que hay que tomar esa información, es ahí donde asoma el despotismo de todos estos personajes lo mismo que sus bases de apoyo; para el argumento que estoy desarrollando resulta más notable que los elementos de la matriz cultural esbozada pueden retratar también a los líderes locales de finales del siglo XIX o a cualquiera de los líderes campesinos de la década de 1920. El caso de Jorge Zúniga es representativo: Zúniga fue presidente del comisariado de uno de los ejidos desde el inicio de las solicitudes, fue directivo del Segundo Comité Agrario Municipal de Atarjea y como tal estuvo involucrado en la tramitación de varias dotaciones más. Para 1926, algunos de los propios beneficiados lo señalaba ya como un autoritario y deshonesto que se enrique- 
cía a costa de la cooperativa ejidal y que ocupaba la oficina del comité para tener encuentros con "su querida". ${ }^{5}$ Por cierto, la facilidad con la que los hombres casados podían hacerse de amantes y a partir de ello ampliar las bases de su parentela, práctica bastante común en la época pese a que en este ejemplo se denuncia como muestra de corrupción, es otro elemento de aquella matriz cultural.

Personajes como Zúñiga, quien un par de años después sería abatido por los cristeros transformando su imagen caciquil en una de mártir agrarista, fueron relevantes porque sobre ellos recayó la generación o actualización de sentidos de autoridad y poder en los ejidos y el municipio. Incluso actualmente es notable la manera en que cualquier viejo ejidatario, y sobre todo quienes han sido identificados por sus vecinos literalmente como los "caciques" (en su connotación de jefes) del municipio entre 1940 y finales de los años setenta, asumen un protagonismo casi absoluto. En sus relatos, el destino del ayuntamiento y de los asuntos agrarios aparecen subordinados en varios momentos a sus disposiciones personales, evidenciando la amplia valoración de un voluntarismo acorde con la imagen de una figura política central y ejecutiva: "cuando yo hice...", "cuando yo era...", "yo les puse el alto...”.

Mi posición es que estos liderazgos se desarrollaron sobre la base de los mismos valores y proyectos que lanzaron al primer plano a los "hijos del pueblo" que encabezaron el Comité Agrario municipal en los años veinte: su arraigo, su condición de patriarcas y hombres duros, y sobre todo su compromiso con las luchas agrarias del siglo XIX, sintetizadas localmente en demandas de justicia agraria en nombre del bien común. ${ }^{6}$ En este sentido, quienes destacaron localmente lo hicieron como representantes legítimos que expresaban no sólo una matriz sino también un proyecto cultural con impulso y requerimientos propios (Ortner 2006, 151).

${ }^{5}$ Archivo del Registro Agrario Nacional (ARAN), Archivo de Dotación, Atarjea exp. 36 I Tomo, $1^{\text {a }}$ instancia mixta (foja 0145), documento de 26 de julio de 1926.

${ }^{6}$ Los tres individuos que inicialmente representaron a los peticionarios del municipio fueron presentados en algunos documentos con el término de "hijos del pueblo". Resulta notable el juego entre su papel de "hijos" y su posición de jefes y patriarcas de familia. 
Pero incluso permitiendo favoritismos, violencia, concentración de poder y abusos locales, ese proyecto habría sido insuficiente por sí solo para consolidar a los pequeños caciques de los ejidos y un paso más arriba a los del municipio. Lo que contribuyó decisivamente a esto en Atarjea, y en municipios aledaños como Xichú, fue la manera en que valores e intereses comunes cristalizaron a través del establecimiento de vínculos de parentela y de intercambio con activistas regionales que devinieron en intermediarios institucionales. Son los casos de Alfredo Guerrero Tarquín (o "el jefe Tarquín", como se le llamaba) y Luis Ferro Medina, quienes de hecho estaban configurando las instituciones posrevolucionarias in situ. Esa tarea reforzaba colateralmente imágenes de dominio, pues requería de comisariados ejidales firmes y autoritarios, leales a los mediadores externos que luchaban por posicionarse en el extremadamente complicado entorno político de la entidad mientras negociaban y presionaban a nombre de aquellos ante las Comisiones Agrarias estatal y federal. En lugares en donde se buscaba hacer triunfar una identidad agraria dejando atrás no sólo la "vocación natural" del entorno (la minería en el caso de la Sierra) sino incluso la definición oficial de Minerales, como ocurría precisamente en los municipios de Atarjea y Xichú, la fundación de los ejidos necesitaba el decidido apoyo de los ayuntamientos. Así que durante varias décadas el movimiento agrario se extendió sobre los cargos públicos coincidiendo con el papel de los caciques como legítimos representantes de "identidades colectivas" basadas en el acceso a la tierra (Knight 2005, 35).

En esos términos resulta comprensible que los destinos de ejidos, municipio y régimen se vieran estrechamente relacionados a partir de la fundación de confederaciones agrarias guanajuatenses en las décadas de 1920 y 1930, cuando se reconvirtieron como parte de la Confederación Nacional Campesina (CNC). Fue entonces que la lucha por la tierra se confundió con "la defensa de la política agraria del régimen” (Martínez Saldańa 1991, 321) o, parafraseando a Abrams (1988), cuando lo desunido adquirió unidad mediante una regulación y dirección moral centralizada. ${ }^{7}$

\footnotetext{
${ }^{7}$ Se puede argumentar que incluso antes de la cNC, fundada en 1938, los campesi-
} 
Pero como he sugerido, los activistas que estaban recreando valores e identidades locales mientras enlazaban y jerarquizaban espacios también estaban involucrados en el reposicionamiento de los grupos políticos que disputaban el gobierno guanajuatense. A estos últimos se les ha identificado en términos generales bajo las referencias de verdes y rojos según su respectiva lealtad política: agraristas a través de las figuras de Obregón y posteriormente Cárdenas, o socialistas comecuras en la estela de Calles. Luis Miguel Rionda ha señalado que ambos tintes no se referían a "identidades ideológicas" -más bien tenues- sino a "lealtades personales basadas en el clientelismo y el interés particular", en donde campeaban un "pragmatismo individualista" y sentimientos identificables "de solidaridad grupal, territorial o familiar" (Rionda 1997a, 14; 1997b, 4-5, 8). Así, la corriente agrarista fue un espacio de disputa y rejuego político sobre diversas posiciones en las instituciones agrarias en formación lo mismo que en diputaciones y ayuntamientos.

Pese a que los vínculos con los ejidatarios son fundamentales, quiero destacar en los apartados siguientes los enlaces de los intermediarios regionales con actores políticos que se movían en el nivel del gobierno de la entidad, cerca del ejecutivo estatal y de la cámara de diputados local, en el frágil y volátil ambiente político guanajuatense de la primera mitad del siglo xx. Sin duda, la única manera de evitar la tergiversación de las capacidades organizativas y de liderazgo que ha sido asociada con cierto estereotipo del cacique (Zárate 2005, 273), y con el cual Ferro y Tarquín podrían ser caricaturizados, es atender sus actividades y sus efectos. Aunque las mediaciones

nos comprometían su apoyo al régimen. Las actas de posesión provisional ejidal contienen el siguiente párrafo que debía ser leído o repetido por el comisariado respectivo al recibir la tierra: "En nombre de los campesinos de mi pueblo declaro que son de recibirse y se reciben las tierras con que se nos dota por mandamiento del C. Gobernador del Estado; que nos comprometemos a respetar las cosechas que haya pendientes, que nos sujetaremos, para la buena administración de nuestro ejido, a las disposiciones dadas o que en lo sucesivo diere el Gobierno Federal y que procuraremos siempre prestar toda nuestra ayuda, tanto al Gobierno de la república, presidido por el C. Gral. Lázaro Cárdenas, como al del Estado, que preside el C. Luis I Rodríguez, para el sostenimiento de las Instituciones emanadas de la revolución". ARAN, Ejido El Carricillo, Expediente general de dotación 104, Foja 0126, acta del 22 de agosto de 1937. 
MAPA. Guanajuato y sus municipios.

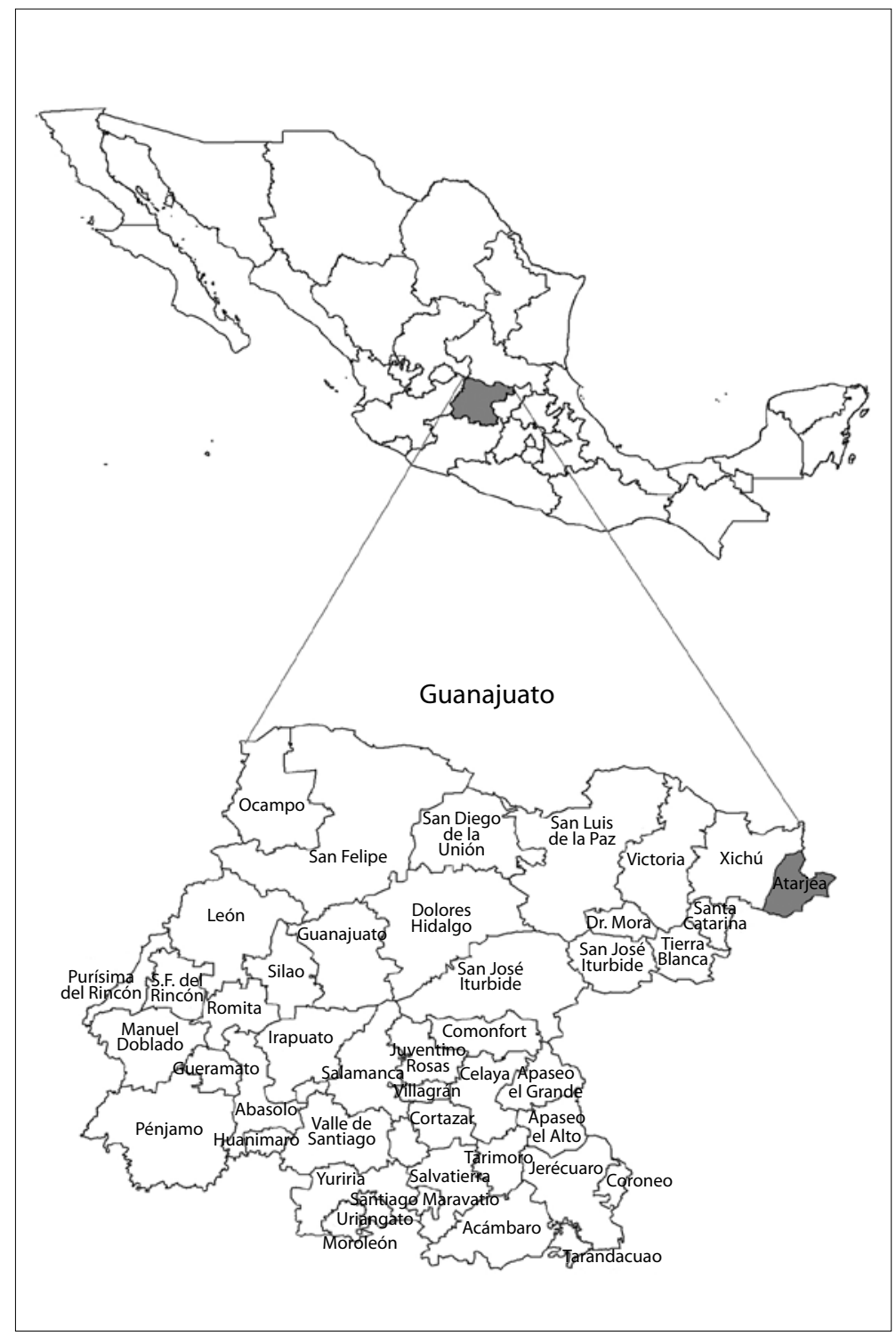

Fuente: Elaboración propia. 
de ambos tuvieron mucho que ver con los ejidos y los ayuntamientos de prácticamente todos los municipios serranos, desde Santa Catarina y Victoria hasta San Luis de la Paz y San José Iturbide, me interesa destacar los de Atarjea y Xichú, los de más difícil acceso hasta la fecha y los únicos cuyos territorios fueron reorganizados totalmente en términos ejidales (véase mapa). Lo que ocurrió en estos municipios resulta fundamental para comprender el dominio de la posrevolución en la Sierra Gorda guanajuatense. En este sentido ha sido muy útil la bibliografía ya conocida, que incluye las extraordinarias memorias de Tarquín, en donde los militantes y caciques campesinos aparecen retratados con admiración y honestidad pero también con cierto cariño condescendiente; del mismo modo han sido de utilidad varios documentos de archivo referidos al tema, además de información original de campo.

\section{LOS VÍNCULOS DE UN INTERMEDIARIO}

Tal como lo deja ver en sus memorias y reminiscencias, Guerrero Tarquín logró constituirse en un mediador político muy efectivo construyendo él mismo sus redes de amistad y lealtad (Guerrero 1987, 1988). El nacimiento de su conciencia política, por decirlo así, se dio en medio de la inestabilidad derivada del cuartelazo de Victoriano Huerta contra el presidente Madero. San Luis de la Paz era entonces el punto de referencia laboral, político y administrativo de buena parte de la Sierra, así que su residencia en el lugar, sumada a sus viajes al interior serrano en la década de 1920, a sus vínculos con mineros y con jornaleros agrícolas, y a su oposición declarada contra grandes propietarios -reorganizados ellos mismos frente al incipiente agrarismo-, comenzaron a hacerlo visible como un líder progresista.

Aun hoy, entre varios ejidatarios atarjenses la visión que se tiene de él es contradictoria pese a que no se pone en duda la influencia política que logró y mantuvo prácticamente hasta la década de 1970 a través de la CNC, la Liga Regional Agraria y la Procuraduría de Asuntos Agrarios de Guanajuato, a la que llegó a trabajar a mediados de la década de 1960: "ese era nuestro jefe que nos venía a 
ayudar aquí a hacer negocios, se llevaba nuestros negocios a Guanajuato"; o bien

Guerrero Tarquín era buena persona, estuvo cuando los primeros ejidos [1920 - 37] y [hasta] cuando Torres Landa y Manuel M. Moreno [19611973] en sus gobiernos. Con él recurría la gente en la Liga de Comunidades Agrarias, era bien vivo. Siempre le decía a uno que sí, y luego al contrario también le decía sí, tú tienes la razón. Tarquín a todos les decía que sí, era muy político. Decía sí sí pero ya hace hambre, invíteme a comer. ${ }^{8}$

Para entender su longevo desempeńo y las diferentes visiones sobre su persona es necesario ponerlo en contexto.

\section{EL AGRARISMO SERRANO: POLÍTICA, MILITARISMO Y PARENTELA}

El punto de partida puede ser la influencia política del general Obregón, evidente desde antes de su candidatura presidencial en 1919, pero que marcó el derrotero político de Guanajuato hasta su presidencia y sobre todo a partir de los sucesos de 1923. Como respuesta a la rebelión delahuertista de ese año el gobierno "reforzó las defensas civiles" (Blanco et al. 2000, 190), removiendo a las autoridades de muchos de los municipios de la entidad "con el objeto de rodearse de ciudadanos adictos al Gobierno y que también reuniesen las condiciones de energía, actividad y honradez indispensables" (Guanajuato 1991, 257-258). Esa “adicción” se expresó en las juntas de administración civil y en la formación de comités agrarios municipales asesorados por activistas como Tarquín. Gracias a esto se logró la entrega provisional de ejidos a los peticionarios de Atarjea y de otras zonas serranas en 1924. Tanto la organización de peticionarios como la dotación de tierras iba aparejada a la formación de "cuerpos rurales militarizados" armados por el propio gobierno y perfilados a la defensa de los ejidos ante la reacción de grandes propietarios que, al menos en la zona de Atarjea y Xichú, eran más renteros de tierra que ganaderos y productores de granos.

\footnotetext{
${ }^{8}$ J.D., Atarjea, entrevista, 2/XII/04.
} 
Es en ese sentido que el reparto debe contemplarse en términos que trascienden lo agrario (Knight 1995). Para el norte guanajuatense, Sepúlveda (2000) ha destacado que la entrega de tierras tenía realmente un fin político-militar y en efecto, cuando se dotaban se nombraba un jefe de armas por cada ejido, subordinado a un jefe de defensas rurales de la zona. $\mathrm{Al}$ respecto, el propio Tarquín menciona afectuosamente en sus memorias a Perfecto González y a sus entonces pequeños hijos, Pablo y Julio, vecinos de Xichú (Guerrero 1988, 86-87). Perfecto, comerciante y jefe campesino de la primera hora en su localidad, mantuvo una relación estrecha con aquel líder, surgida inicialmente en el interés por el reparto de tierras pero profundizada en la segunda mitad de los ańos veinte, durante la lucha contra varios movimientos políticos opositores, algunos básicamente guanajuatenses y otros de mayores alcances, como la Cristiada. La perspectiva sobre las relaciones de amistad y patronazgo como elementos "intersticiales" que permiten la articulación y funcionamiento de un entramado político formal y legal, señalada por Wolf (1990), es reveladora en este caso porque el enlace político militar se generó entre Tarquín en San Luis de la Paz, su amigo Perfecto González como cabeza de la organización política de la zona (Xichú), y un peldaño más abajo y poco después el cuñado de éste último, Guadalupe Hernández, de Aldama (Atarjea), a su vez jefe de defensas rurales de la zona. Pero como veremos enseguida la historia de este nexo es más larga.

A partir del aplastamiento del delahuertismo y hasta 1927, el gobierno de la entidad estuvo en manos de varios gobernadores constitucionales e interinos hasta la clara redefinición de los bandos políticos evidenciada en la disputada elección por la gubernatura entre el diputado federal Agustín Arroyo Ch., verde afín a Obregón, y el rojo general callista Celestino Gasca, comprometido con los latifundistas del norte de la entidad. ${ }^{?}$

${ }^{9}$ La tensión entre las fuerzas callistas y obregonistas en Guanajuato queda bien retratada con la sucesión de casi una treintena de gobernadores, constitucionales, suplentes e interinos, entre 1920 y 1940 . Si bien, el paso de muchos de ellos fue fugaz, al menos una oncena tuvo una labor política trascendente con compromisos definidos a favor o en contra del reparto agrario. 
Tarquín trabajó activamente en esta campaña electoral, que registró irregularidades precisamente en los municipios de Victoria y Xichú, lugares sensibles a su influencia. La victoria de Arroyo Ch. derivó en la instalación gasquista de un efímero gobierno paralelo encabezado por el caudillo derrotado en San Diego de la Unión, municipio colindante con el de San Luis de la Paz y con el estado de San Luis Potosí, entonces controlado por el general callista Saturnino Cedillo. Esta situación obligó a las fuerzas revolucionarias guanajuatenses a aglutinarse en torno al gobernador, quien amplió su base social a través del fomento al reparto agrario y mediante la emisión de una Ley de Aparcería estatal que limitaba las ventajas de los propietarios sobre los jornaleros agrícolas y los campesinos renteros. Ambos sucesos se verían contestados por el levantamiento cristero en el municipio de Victoria en 1928, que tendría una efectiva respuesta militar, y con el asesinato del presidente reelecto Obregón el mismo año.

Para entonces, Tarquín se había sumado a las tropas del coronel Genovevo Rivas. Con mando del 48 regimiento desplegado en la Sierra Gorda a partir del municipio de Dolores Hidalgo, las fuerzas de Rivas incursionaron repetidamente por Victoria, Xichú y Atarjea haciendo retroceder o al menos conteniendo a numerosas gavillas cristeras (Guerrero 1988). Romana Falcón identifica el quehacer de Rivas conjuntamente con el desempeño militar del general Saturnino Cedillo, que combatió el levantamiento en la Sierra Gorda "en el límite entre San Luis [Potosí] y Guanajuato [...] con casi dos mil agraristas". De acuerdo con ella, para 1928 se recrudeció la guerrilla cristera en la zona y "Cedillo se ganó entonces el mote de 'el terror de la sierra' por la forma sanguinaria en que llevó a cabo su campaña" (Falcón 1984, 188).

En esos momentos, Tarquín se dio a la tarea de consolidar en el noreste guanajuatense los cuerpos rurales serranos, encabezados ya por agraristas que le eran afines. En Atarjea, la jefatura de las fuerzas campesinas recayó en Pino Medellín y en comisariados como Benigno Sáenz, Jorge Zúñiga y Tomás Olvera. Todos ellos cayeron abatidos por partidas de cristeros que incursionaban desde Querétaro al tiempo que las fuerzas agraristas del xichulense Perfecto Gon- 
zález ultimaban en Las Adjuntas a un importante líder cristero, hermano del párroco del municipio de Victoria, durante una "patrulla de inspección”. Cuando las guerrillas cristeras amenazaron Xichú en represalia, Perfecto González y sus fuerzas "se fueron a proteger hasta Atarjea, con los armados de El Charco, que a las órdenes de Baciliso Sáenz [hijo de Benigno] se sostuvieron en su reducto durante toda la campańa" (Guerrero 1988, 61, 220).

Este hecho tuvo una profunda importancia política: durante su estancia en Atarjea, Perfecto González se relacionó con Guadalupe Hernández, el hombre fuerte del agrarismo en la localidad atarjense de Aldama y "comandante de todas las fuerzas rurales militarizadas del municipio de Atarjea” después del asesinato de Pino Medellín (Guerrero 1988, 233). Más importante que eso, Perfecto conoció a una de las hermanas de Guadalupe, con quien posteriormente se casó. De ahí que Perfecto, hombre de todas las confianzas de Tarquín y quien sería el medio político utilizado por éste prácticamente hasta la década de 1970 , se convirtiera en un patriarca o, en otros términos, se hiciera de "muchos parientes" y simpatías políticas en todo Atarjea. Se formó así una parentela sobre puntos geográficos distantes dotados, a partir ella, de una lógica política que trascendía los municipios.

La paz intermitente permitida por cristeros y gasquistas (grupos que eventualmente derivarían en gavillas de bandoleros al servicio de grandes propietarios), representó el acercamiento y articulación definitiva entre mediadores ubicados en distintos niveles y las bases agraristas serranas. La fortaleza de las relaciones convirtieron a Tarquín en un representante legítimo e ineludible para los grupos políticos guanajuatenses que disputaban la gubernatura.

En tanto, la muerte de Obregón desató una crisis política que reorientó la lucha en la entidad hacia el control de la Confederación de Partidos Revolucionarios Guanajuatenses (CPRG), ganado por los callistas pese a las fuertes resistencias verdes (Blanco et al. 2000, 203-204). Desde ahí pudieron construir en 1932 el triunfo electoral de Melchor Ortega, un político muy cercano a Calles, aunque debieron hacerlo contando con los trabajos de activistas verdes como Tarquín, quien incursionaba entonces en las diferentes confedera- 
ciones campesinas de la entidad, en la Acción Social Revolucionaria (grupo constituido en 1932), y en la misma reorganización de la CPRG adherida al naciente Partido Nacional Revolucionario. Ortega requirió de las defensas rurales para combatir "brotes de violencia cristera en varias partes de la entidad" (Valencia 1998, 33), entre ellas el noreste serrano. Simultáneamente el Congreso local modificó los tiempos electorales para hacer coincidentes la elección del gobernador con las de ayuntamientos, por lo cual en 1934 el periodo municipal se acotó a un ańo (Rionda 1996). Todo esto supuso una enorme actividad política y militar que se acentuó con la amplia campaña presidencial de Lázaro Cárdenas, perfilada prácticamente desde 1931.

Bajo la influencia de Calles, Cárdenas asumió la presidencia de la República en 1934 y un año después Jesús Yañez, otro político rojo, resultó electo gobernador de Guanajuato sucediendo a Melchor Ortega. ${ }^{10}$ Mucho se ha escrito de la ruptura entre Cárdenas y Calles y éste no es el lugar para abundar sobre el asunto, baste decir aquí que la influencia del último pudo ser cortada cuando un par de años después el presidente Cárdenas le expulsó del país junto con varios de sus incondicionales, entre ellos Melchor Ortega, tomando previamente la precaución de renovar todo el gabinete con políticos fieles a su persona. Como efecto de lo anterior, el Senado de la República declaró desaparecidos los poderes en Guanajuato ungiendo como gobernador provisional al diputado Enrique Fernández Martínez, quien se mantuvo en el cargo hasta 1937 siguiendo la política agrarista del cardenismo (Rionda 1996). Pese al perfil político de Fernández hay que decir que no se trataba de un gobernador con el que Tarquín tuviera una buena relación justamente porque en la Sierra existía otra mediación agrarista menos radical.

En 1937, se realizaron elecciones para el gobierno de la entidad, triunfando claramente quien fuera secretario privado de Cárdenas, Luis I. Rodríguez. Coincidentemente en estos ańos se celebraron un

${ }^{10}$ Yañez tuvo como Secretario de Gobierno a Manuel M. Moreno, quién llegaría a la gubernatura en 1967 sucediendo a Juan José Torres Landa, un gobernador con antecedentes verdes. 
par de Congresos Agrarios en León y Celaya que sirvieron para el realineamiento político en la entidad. Estos escenarios, en donde los "presidentes municipales" encabezaban "las representaciones campesinas de cada pueblo" (Guerrero 1987 tomo 2, 119), fueron bien aprovechados por la fogosa oratoria de Tarquín, quien logró un gran acercamiento con el gobernador Rodríguez y eventualmente con el propio presidente Cárdenas.

Sumado a lo anterior, su control sobre las milicias campesinas le resultó sumamente redituable cuando el gobernador Rodríguez planeó en ese mismo año una gira por la Sierra Gorda para visitar Xichú y hacer entrega formal de las carpetas ejidales a los comisariados de varios de los municipios serranos. Tarquín cuenta que ante la reticencia de los militares, que asumían los peligros de la incursión en una región en la que se sentía la influencia del general Saturnino Cedillo (entonces distanciado de Cárdenas), y que además era campo de acción de partidas de cristeros, él mismo ofreció garantías totales al gobernador echando mano de su armada agrarista. Es decir, utilizando al grupo de fuerzas rurales encabezado por Guadalupe Hernández en Atarjea, y el apoyo de Perfecto González que en esos años presidía además la Junta de Administración Civil de Xichú. De acuerdo con Tarquín, "la recepción de Xichú revistió caracteres de apoteosis", llegó "un río humano" de campesinos (1987 tomo 2, 296-297), muchos de ellos provenientes de Atarjea para un evento con la plana mayor de la política guanajuatense reunida para el efecto: el gobernador, autoridades de la comisión nacional agraria, intermediarios, líderes locales, y todos los nuevos comisariados.

El peso y el efecto de estos rituales de legitimación no debe ser subestimado pues están en la base política del régimen posrevolucionario: la entrega de carpetas ejidales reunían con un mismo propósito, y pretendidamente bajo una misma visión de pasado y de futuro (respectivamente una respuesta a las reformas liberales del siglo XIX y una perspectiva de justicia social), al campesino más desposeído y al gobernador como jefe y vanguardia política. Suponía también la oficialización de las comunidades rurales formadas como efecto de las dotaciones agrarias y la presentación del ejidatario como el nuevo sujeto social en el campo serrano. 
Tampoco se debe pasar por alto que las mediaciones y la jerarquía política y militar del espacio, crucial en la organización y contención de la violencia, se fueron forjando en un ambiente de confusión social alimentado por numerosas cuestiones, entre ellas el tortugismo en la dotación -los peticionarios atarjenses de Mangas Cuatas se quejaban en 1934 que su "asunto" había estado "dormido de diez a doce años" mientras un poco después los de Aldama se deslindaban de Tarquín en busca de otra mediación más efecftiva-, por las guardias blancas de los grandes propietarios que se resistían a perder sus agostaderos, por la ausencia de deslindes agrarios, un problema con raíces históricas muy profundas en la Sierra, etcétera. Además, la reacción local ante la entrega de tierras fue matizada, algunos las aceptaban de manera entusiasta pero otros lo hicieron por consideraciones meramente prácticas: "para mantener la unidad", "para no salirse de su lugar", o en espera de extensiones apropiadas para la ganadería; otros por el contrario "se fueron [...] aunque fueran criollos [criados en el lugar]". ${ }^{11}$

Pese a esos problemas, o quizá por los mismos, la entrega de tierras en 1937 supuso el afianzamiento de Tarquín como político serrano. En paralelo a su influencia militar, este líder había mantenido su activismo en la Liga Regional Campesina "Guadalupe Olvera" (fundada en 1936) y su desempeńo como tesorero de la Liga de Comunidades Agrarias del Estado, luchando desde esas posiciones para ubicar a su gente en diputaciones y cabildos, "logrando acercar mi agrarismo a las presidencias municipales” (1987, 299-300). Como parte de su posicionamiento debió enfrentar la confusión y tediosa tramitología que se generó inmediatamente después del reparto con respecto a las tierras dotadas a varios ejidos de Atarjea.

En efecto, el problema fue que lo repartido en realidad provenía de las tierras que el empresario Federico Ernest había utilizado como propias y no de la hacienda de Charcas como aseguraba la documentación, lo que abrió momentáneamente un flanco para que la sucesión del empresario peleara nuevamente "su" propiedad en una situación muy parecida a lo acontecido en Xichú, donde al-

\footnotetext{
${ }^{11}$ Atarjea, diversas entrevistas, 2004-2008.
} 
gunos antiguos propietarios recuperaron tierras en perjuicio de los ejidatarios. ${ }^{12}$ A esto se sumó la manera en que se hicieron las propias delimitaciones. Algunos ancianos recuerdan que los agrimensores midieron "a ojo" buscando protegerse de francotiradores y gavillas de distinto signo político que merodeaban por la sierra. Estos trabajos fueron eventualmente utilizados como base para el quehacer de ligas agrarias, de confederaciones campesinas y del Registro Agrario Nacional dando pie a profundas animadversiones al interior del mismo municipio y al empantanamiento de los problemas, pues las mediciones exactas que aún hoy continúan demandando unos restarían a otros franjas de tierra que han trabajado ya durante décadas. Además, muchas de esas tierras habían sido abiertas al cultivo por los propios campesinos, cosa que reconocían los agrimensores del gobierno, de manera que la parcela misma remitía a la memoria de su creación y a los derechos del ejidatario sobre ella.

Involucrado en el arreglo de esas problemáticas como líder cenecista, el aprecio del gobernador se le haría evidente a Tarquín poco después, al ser enterado que el PNR le había designado candidato a la presidencia municipal de San Luis de la Paz. En sus palabras el gobernador le informó en persona lo siguiente: "Serás en esta hornada de presidentes municipales, el único que tendrá acción civil para administrar y mando militar para mantener la paz, por el funcionamiento de tus aguerridas defensas agraristas que tan bien controlas y diriges en beneficio del gobierno legítimo" (Guerrero 1987, 307).

En esos ańos se incubaban tanto la rebelión del general Cedillo contra el presidente Cárdenas como la nacionalización de la industria petrolera. Romana Falcón ha seńalado que en ese entonces Cedillo "tenía relaciones con la nueva avanzada de cristeros", y pese a que al explotar la rebelión en mayo de 1938 las "ramificaciones" de la misma eran débiles (Falcón 1984, 260), el rebrote cristero de 1937 y 1938 se llevó de un golpe a cuatro agraristas de Aldama y a dos más de Xichú. La situación empujó a Tarquín a incursionar en la Sierra en apoyo del jefe político y militar de aquél municipio,

\footnotetext{
${ }^{12}$ ARAN, Expediente Ejidal General, Expediente de Dotación, Ejido Mangas Cuatas, situación referida en carta de abril de 1940.
} 
Perfecto González, a quien los cedillistas habían pedido en dos ocasiones la entrega de la plaza (Guerrero 1987, 337). Para entonces los mandos de las fuerzas militares dispuestas en la Sierra ya se habían reconfigurado, pues el ya general Rivas Guillén, exjefe militar de Tarquín y pieza política de Cárdenas, había sido nombrado gobernador de San Luis Potosí (Falcón 1984, 266).

El contrapeso a la carrera ascendente de Tarquín lo marcan tres asuntos. El primero fue que las secuelas de la indefinición de linderos entre ejidos le generaron animadversiones que encontrarían en breve un espacio de expresión bajo la figura de Luis Ferro Medina, el otro intermediario político serrano del que nos ocuparemos posteriormente, de un perfil más moderado y con nexos que a la larga probaron ser más efectivos pese a los vaivenes de la vida política de la entidad. Precisamente, el segundo asunto fue un cambio político crucial: lamentablemente para las aspiraciones de Tarquín, Luis I Rodríguez pidió licencia al ser llamado por el presidente Cárdenas para encabezar la transformación del Partido Nacional Revolucionario, del que esa agrupación saldría renovada y libre de callismo con el nombre de Partido de la Revolución Mexicana; Rodríguez sería el primer presidente de su comité central (Rionda 1996). Entonces, el gobierno de Guanajuato recayó brevemente en Rafael Rangel, exsecretario particular del rojo Melchor Ortega, situación que sirvió para que los verdes se aglutinaran tras Enrique Fernández Martínez, el mismo exdiputado local (1924-1926), exgobernador provisional (1935-1937) y exdiputado federal (1939) con el que Tarquín mantenía relaciones tirantes. Presuntamente apoyado por la diputación local, que entonces presidía Luis Ferro Medina, Fernández se presentó como candidato y triunfó sin mayor oposición.

Finalmente a todo lo anterior se suma el hecho de que el Jefe de Operaciones Militares del Estado y el Comandante del Sector Militar se posicionaron de manera favorable en esta coyuntura política en beneficio del nuevo gobernador y de sus redes, acotando poco a poco el mando militar informal que Tarquín mantenía en la Sierra. El mismo personaje relata cómo fue amenazado de muerte por aquel comandante, quien tuvo mando de tropa contra el cedillismo en San Luis de la Paz, Atarjea, Xichú y Victoria, y cómo eso acarreó 
que alguno de sus amigos agraristas se alejara de él para acercarse al otro intermediario (Guerrero 1988, 232). Como metáfora de su situación Tarquín apuntó en sus memorias que "El viento había cambiado y el sol nos daba la espalda" $(1988,87)$, y en efecto, al declive del cardenismo él mismo debió separarse de la presidencia municipal de San Luis de la Paz supuestamente por disposición del propio presidente Cárdenas, quien le ordenó atenderse viejas heridas de guerra. Su municipio quedó entonces bajo la influencia política de Ferro.

Apenas repuesto de salud, Tarquín se internó en la Sierra con rumbo final hacia Atarjea buscando medir las fuerzas y el ánimo de sus bases rurales ante la gubernatura de Fernández y de cara al avilacamachismo en ciernes. Lo que encontró -grupos campesinos con identidades ejidales bien asumidas- le permitió redefinirse eventualmente según la coyuntura política: como aliado circunstancial de aspirantes a puestos públicos o como oposición priista interna frente a gobernadores y diputados cada vez más alejados de los ideales agraristas. En paralelo, a inicios de los ańos cuarenta Luis Ferro acrecentaba su perfil progresista desempeñándose en el congreso local y participando ahí mismo como secretario de un "Bloque Democrático Revolucionario" articulado en apoyo al gobernador (Rionda 1996, 48).

En esa década, Tarquín acusó a Ferro de estar cooptando líderes locales en la zona; el caso que le pareció más evidente y doloroso fue el del líder del ejido atarjénse de Aldama, Guadalupe Hernández, muy amigo suyo tal cómo él mismo narra, pero quien pese a eso "chaqueteó" redefiniendo sus lealtades pasando al bando de Ferro cuando pensó que Tarquín estaba políticamente acabado (Guerrero 1988, 230, 232). ${ }^{13}$ No obstante lo costoso en términos políticos y personales, este tipo de rupturas y reacomodos podían matizarse a través de relaciones de parentesco y amistad que involucraban a las redes políticas del noreste de la entidad: si Hernández tenía una línea no cancelada con Tarquín a través de su cuñado, el líder xichulense

${ }^{13}$ Este nexo debió reestablecerse en la década de 1950 cuando las diferencias entre Tarquín y Ferro se suavizaron como efecto del fin del reparto agrario en la entidad y del retroceso del agrarismo como corriente política. 
Perfecto González, también podía acudir a Ferro mediante otro de sus cuñados, don León Vela, líder del ejido de Atarjea, en su momento presidente municipal y fiel seguidor de Ferro. ${ }^{14} \mathrm{El}$ matrimonio de Vela con otra hermana de Guadalupe Hernández facilitó que una misma línea de parentesco y todos sus patriarcas se encontraran relacionados con los dos cacicazgos regionales.

El ámbito en donde lucharon los agraristas luego de su repliegue ante el evidente éxito de los amparos agrarios y los certificados de inafectabilidad promovidos por el propio gobierno avilacamachista fue el electoral. Resulta revelador el hecho de que en 1942-1943 no se pudieron realizar elecciones en la zona de influencia de Tarquín, en San Luis de la Paz y Xichú -él narra que un año antes había logrado colocar a partidarios suyos en algunas presidencias municipales, entre ellas Atarjea- repitiéndose los problemas electorales para 1947-1948 en San Luis de la Paz (Rionda 1997a, 59 y ss). Aunque investigadores como Rionda señalan que "las elecciones fueron, hasta 1946, un asunto de control esencialmente municipal" $(1996,17)$ es claro que incluso después de esa fecha las autoridades municipales mantuvieron una enorme influencia en la realización de comicios.

Tarquín había quedado disminuido al ser despojado de su mando militar, sin embargo pudo encauzar su activismo a través de la burocracia agraria. Y era ahí donde había un amplio campo de mediación política (y de ganancia electoral) dada la tensión y el encono al que se llegó. Por ejemplo: durante un par de décadas se querellaron campesinos del ejido Los Álamos y Los Llanitos (de Atarjea, como todos los que mencionaré enseguida) con ejidatarios del municipio de Xichú; los de El Carricillo y La Joya, pelearon entre sí varios ańos por un paraje que producía cantidades significativas de piñón; los de Los Álamos mantienen aún hoy un pleito con Mangas Cuatas por 33 hectáreas; los ejidatarios de El Toro derribaron apenas en marzo de 2008 las mojoneras que señalaban los límites con El Carricillo; en San Antón se mantiene un diferendo con La Joya por

${ }^{14}$ León Vela es un seudónimo. Hasta hoy don León culpa directamente a Tarquín del traslape de linderos ejidales, "Por iniciativa de él fraccionaron cuatro ejidos sobre el nuestro, [lo hizo] para controlar políticamente" dice, de ahí su acercamiento con Ferro. L.V., Atarjea, entrevista, 2/XII/04. 
linderos; los de Atarjea y El Banco se enlazaron en apoyos y disputas contradictorias y constantes: conflictos entre vecinos, abusos de las defensas rurales en contra de campesinos desarmados, compras fraudulentas de parcelas evitadas por el empeño del Comité Regional Agrario en impedir el "acaparamiento de parcelas", pleitos por la destrucción de cultivos generada por ganado libre, quejas por la extracción ilegal de material en zonas ejidales, y otras tantas ligadas a los notables retrasos en la renovación de las autoridades ejidales. ${ }^{15}$

Desde su papel como ejecutivo de la CNC, y desde la amistad y fidelidad ganadas en épocas de violencia armada, Tarquín pudo maniobrar en las décadas siguientes para que las tensiones locales no se desbordaran -una proeza no menor-ejerciendo su influencia sobre los caciques ejidales y maniobrando a la hora de la designación de candidatos en algunas de las alcaldías serranas, entre ellas Atarjea y Xichú. Lo hizo a través de Perfecto González y de sus hijos Pablo y Julio, identificados estos últimos como "comerciantes, políticos y maestros" por mucha gente (actividades con las que, además, ampliaron posteriormente su quehacer en el otro sector priísta, la Confederación Nacional de Organizaciones Populares). Un vecino de Atarjea los describe con algunos de los valores patriarcales a los que aludí al inicio:

Los González eran grandes políticos de Xichú, ellos dominaban, eran los que decidían en los cincuentas, en los sesentas, hasta en el ' 69 ponían presidentes. En todas las comunidades había un líder, la gente los seguía, era ley lo que decía. Y ya venía la orden de Xichú, quién era al que ponían de presidente [municipal]. Eran a través de los comisariados o a través de los líderes naturales; que ya se venía un cambio de presidente y con esos se dirigían. Tenían tanto poder que los iban a ver allá a Xichú, ¿quién cree que esté bueno para presidente? Casi eran designaciones, pero había que hacerlo de forma legal, con el Consejo Municipal Electoral le hacían la cosa legal. Luego les decían "van a venir a votar", llegaba uno con todas las credenciales, les decían cómo cruzar las boletas y luego "cuéntele las boletas". ${ }^{16}$

${ }^{15}$ Información obtenida de las carpetas de los ejidos señalados, ARAN.

${ }^{16}$ P.J.D., Atarjea, entrevista, 29/II/08. 
En efecto, el papel de los González era determinante. Siendo un miembro importante de la Liga de Comunidades Agrarias, don Perfecto se desempeńó como comisionado de la CNC estatal en la región, una posición políticamente crucial en dos niveles: A través de él, se elegían representantes al Comité Regional Campesino, cuyo Comité Ejecutivo presidía Tarquín, y fungía como correa de transmisión de la CNC estatal, donde Tarquín era Secretario de Acción Agraria y Sindical. En otros términos, ellos representaban al PRI cuando debían definirse las candidaturas a la presidencia municipal en Xichú y Atarjea.

Además, como parte de su comisión cenecista, don Perfecto era el medio a través del cual los ejidos atarjenses canalizaban 5 por ciento de sus cosechas a manera de contribución para la Delegación de Promoción Ejidal. Incluso tenía facultad para nombrar uno o dos delegados con funciones políticas y electorales en cada uno de los doce ejidos existentes en Atarjea, en los que contaba con parientes y amigos, de manera que "se metían en todos los ejidos de Atarjea. La política estaba en favor de ellos"; o bien, "era un pequeño grupo de gente la que decidía aquí [...] Eran del pueblo algunas de las gentes que decidían, los cenecistas decidían en sus convenciones. Allá en Xichú decidían, era el lugar más próximo". ${ }^{17}$

La influencia de don Perfecto y sus hijos sobre la alcaldía xichulense, sobre el Comité Regional Campesino y dentro del sector campesino del PRI fue perdurable. Gracias a eso Julio González fue presidente municipal de Xichú en 1961-1963 y nuevamente en 1977-1979, además de diputado local suplente en la década de 1960. Los más ancianos aseguran que fueron los González quienes hasta los setenta organizaron actos de campaña en la región para los candidatos de ese partido a diputaciones y al gobierno de la entidad, solicitando a sus subordinados en Atarjea y en otras partes de la zona el envío de contingentes para mítines y reuniones: "era una cosa muy descarada”, "Vamos a recibir al candidato' decían los González, 'tráete tantos animales' y la gente iba”. En consecuencia,

${ }^{17}$ Atarjea, diversas entrevistas de campo, 2004- 2008. 
como se recuerda, "la gente iba a Xichú a solucionar problemas... pero ahí los entretenían". ${ }^{18}$

\section{EL OTRO INTERMEDIARIO}

Como he señalado, no hubo un único cacique regional. En San José Iturbide, municipio contiguo a Querétaro y ubicado también en los márgenes de la Sierra, emergió en la década de 1920 la figura de Luis Ferro Medina, por un tiempo némesis política de Tarquín, a quién éste mismo identificaba como un líder muy astuto, abusivo con las contribuciones campesinas en su jurisdicción, interesado en el "alpinismo político" y en beneficiarse personalmente de las minas serranas. ${ }^{19}$ De acuerdo con Tarquín el papel de Ferro dentro de los grupos revolucionarios era discutible porque además contaba con financiamiento de terratenientes, cuatreros y grupos cercanos a la iglesia católica (Guerrero 1987, 366; 1988, 231); los denuestos, posiblemente exagerados, son suficientes para comprobar que la posición regional de este líder era una amenaza directa para la construcción de una sola vía de intermediación política.

Originario de San Miguel de Allende, Luis Ferro Medina trabajó como rayador en la hacienda de San Diego de las Tránsquilas, cuyos dueños -la familia Sautto- confiaban su administración a Gustavo de la Sota Caballero, eventualmente suegro de Luis y amigo del jefe político de San José Iturbide, Alberto Ferro Torres, padre del propio Luis. Con estos puntos de partida Ferro Medina construyó una larga carrera política a partir de su acceso a la presidencia municipal de San José Iturbide en 1931, labor en la que contó entre sus regidores a sus hermanos Genaro y Lauro, este último también presidente municipal por un breve periodo en 1936.

${ }^{18}$ R.G., Atarjea, entrevistas, 2/XII/04.

${ }^{19}$ Un historiador iturbidense describe a Luis Ferro en claroscuro: siempre a favor del agrarismo, "De mediana estatura, delgado, moreno, discreto, tímido, de carácter apocado, hacía uso de fórmulas convincentes en sus relaciones humanas, pues era partidario en todo de la conciliación. Siendo un abarrotero modesto y de pocas luces, extraña haya prosperado en la política" (Munúuzuri 1997, 104-105). 
A través de relaciones de amistad los vínculos de Ferro se extendían hacia familias económicamente importantes en San Luis de la Paz (los Gamba, los Ducoing), y con otras tantas de Victoria (los Charre y los Chaire), manteniendo paralelamente su influencia sobre San José Iturbide y San Miguel de Allende, sitio en donde radicaba el Partido Judicial al que Atarjea estaba adscrita. Gracias a esto logró influencia en las zonas que Tarquín asumía como propias, mientras que este último intentaba con menos fortuna consolidar su presencia en los municipios en los que se desempeñaban los Ferro. ${ }^{20}$ Siempre de acuerdo con Tarquín, los Ferro eran el vehículo para que latifundistas de San José intentaran hacerse con la diputación local correspondiente a San Luis, "a lo que siempre nos opusimos los de San Luis de la Paz" $(1988,13)$. Al momento, San Luis y San José estaban ubicados en diferentes distritos políticos, lo que les permitía un diputado a cada cual en la Cámara de la entidad. En la federal compartían el $9^{\circ}$ distrito (junto con San Miguel de Allende, Dr. Mora, Xichú y Atarjea), lo que les confrontaba por una diputación.

Pero fue un poco antes que los agraristas de San Luis de la Paz se distanciaron de los de San José Iturbide. El alejamiento y la oposición está relacionada con la dotación ejidal en San Diego de las Tránsquilas (y en donde supuestamente Lauro Ferro estuvo involucrado en la venta de parcelas al mejor postor), y más ampliamente con el control del municipio en el que se ubicaba ese predio, el de Dr. Mora, creado al calor de la lucha agraria durante los treinta con porciones importantes de San José. ${ }^{21}$ Divisiones como ésta, entre los verdes, facilitaron la violenta reacción del grupo rojo en la lucha por el control de la entidad a la muerte de Obregón; como parte de estas tensiones Alberto Ferro fue detenido y murió en prisión,

20 "Era desesperante para Luis Ferro que yo le disputara el control del campesinado en su propio distrito, y mucho más aún que obstaculizara sus pretensiones a la cámara federal, cosa esta que tampoco me perdonaba don Enrique [Fernández] por la alta estima en que tenía al pretendiente" (Guerrero 1988, 104). En contraste, un hijo de Luis Ferro asegura que su padre sí tenía influencia en los municipios controlados por Tarquín -información corroborada por varios viejos ejidatarios atarjénses- mientras que éste carecía de presencia en los afines a Ferro, como San Miguel de Allende.

${ }^{21}$ El municipio de Dr. Mora tiene su propia dinámica: fue fundado en 1935 y al final del cardenismo desapareció para resurgir redefinido durante la década de 1950. 
mientras que su hijo Miguel Ferro, agrarista y militante anticristero, cayó asesinado años después (Guerrero 1988, 13; Munúzuri 1997, 107-108).

Así Luis Ferro se vio impulsado a encabezar el agrarismo en San José Iturbide y, por condiciones de sus mismas redes, a competir con Tarquín desde diversos frentes: las distintas candidaturas, las posiciones al interior de las Ligas Agrarias e incluso el quehacer cotidiano de gobierno organizado desde San Miguel de Allende: Tarquín acusaba a Ferro de utilizar en su beneficio las oficinas recaudadoras para saquear "los poblados [entre otros los de Atarjea] a nombre del gobierno" a través de su hermano Miguel, que entonces se desempeñaba "como auxiliar y empleado de confianza" (Guerrero 1988, 219).

Ferro logró moverse con audacia durante la consolidación de la posrevolución. Fortalecida su posición durante el cardenismo, su papel en la cámara de diputados y su afinidad con el gobernador Enrique Fernández le permitieron aprovechar la ausencia de Tarquín en la Sierra entre 1939 y 1940 influyendo directamente en el ayuntamiento de San Luis de la Paz; después saltó de lo agrario a lo urbano y de lo regional a lo estatal. Durante los años de 1940 desempeñó labores sindicales en el sector salud cuando trabajó en esa secretaría en la capital del país; después de un periodo de bajo perfil asociado con un paso político en falso, llegó a ser diputado federal en 1957 y luego Secretario de Tránsito del Gobierno del Estado de Guanajuato desde 1961 hasta 1973, sorteando en 1967 la ruptura acre entre los gobernadores saliente y entrante (respectivamente Torres Landa y Manuel M. Moreno). ${ }^{22}$ En su momento promovió grandes comilonas en honor del exgobernador cardenista Fernández, una forma muy efectiva de hacer política y de refrendar lealtades personales. Uno de sus hijos las recuerda de esta manera:

Yo le ayudé a mi papá a hacer los sobres de la "comida de la amistad", cada año, en honor de don Enrique Fernández Martínez. Se llenaba todo el

${ }^{22}$ L.F.S., San José Iturbide, entrevista, 25/II/08. En la estela de su padre, uno de los hijos de Ferro llegó a ser presidente municipal de San Miguel de Allende en la década de 1980. Otro de ellos fue presidente del Comité Estatal del PRI en 1991. 
centro de San Miguel de Allende de gente, arriba y abajo. Camión con leña y reses en canal. De San José Iturbide asistía gente como José Zarazúa, los Garfias y otros, eran comidas de unas cuatro mil gentes. Iba el gobernador, fue Aguilar y Maya, luego el doctor Rodríguez Gaona, [asistieron] siendo gobernadores. Este último le entregó [el cargo] a Torres Landa. Eran comidas políticas, no podía faltar "estrellita marinera", que era como un himno del partido verde. Ahí estaba la gente de más valía, los rojos también eran de Guanajuato pero vivían en México, eran valiosos pero no al grado de que se creían príncipes. En el fondo ambos grupos se reconocían sus capacidades. Ya cuando [mi papá] se fue a Tránsito del Estado dejó de hacer estas comidas, don Enrique se deterioró en salud y falleció después. Gracias a don Enrique fue gobernador Torres Landa. Arroyo Ch. [ex gobernador previo a Fernández] y don Enrique ayudaron en eso. Y aquí [lo hizo] mi papá. ${ }^{23}$

Por la temprana construcción de estos vínculos y por la posición que facilitaban, Ferro llegó a constituirse desde los treinta como una alternativa real para grupos y líderes ejidales atarjenses frente a problemas agrarios y ante la ausencia de apoyos al municipio. Su influencia en el proceso agrarista, que se mantuvo pese a sus desempeños en ámbitos de gobierno ajenos al agrario y más cercanos al sector popular del PRI, queda ejemplificada cuando desde su cargo en la CNC Tarquín solicitó a las instituciones agrarias el envío de ingenieros agrimensores para resolver problemas de linderos sobre los ejidos atarjenses de Mangas Cuatas, El Banco, El Charco, Cerro Prieto y Atarjea. Este líder pidió literal y enfáticamente que no fueran agrimensores residentes de la "brigada del norte", asentada en San Miguel de Allende, una de las bases de poder de Ferro, "porque sabemos de sobra que estos señores nos perjudicarán en vez de ayudarnos. Esta última súplica se la encaresemos más, porque encarna para nosotros un verdadero peligro si se encomienda esta

${ }^{23}$ L.F.S, San José Iturbide, entrevista, 25/II/08. Es necesario agregar que el exgobernador Fernández Martínez se estableció en San Miguel de Allende en los cincuenta, teniendo ahí intereses inmobiliarios y fungiendo poco después como asesor de los presidentes Adolfo López Mateos y Gustavo Díaz Ordaz (Rionda 1996, 55). 
comisión al personal antes citado". ${ }^{24}$ No era una petición vana ya que los extensionistas eran capaces de meter en problemas a caciques beligerantes obstaculizándoles el cumplimiento de las exigencias de sus clientelas.

Pero el perfil político de mayor alcance de Ferro, su interés en municipios de mayor peso político y productivo en el noreste de la entidad, como San José Iturbide, San Miguel de Allende y Dr. Mora, y su propio desempeńo como empresario agrícola, ${ }^{25}$ permitieron a Tarquín mantener sus redes personales y sus labores de intermediación a través de la CNC en municipios económicamente empobrecidos a partir de poblaciones depauperadas como la Misión de Chichimecas en San Luis de la Paz, o en los municipios amestizados de Atarjea y Xichú. ${ }^{26}$ Además de los nexos de lealtad, la extensión de la Sierra y la dificultad misma de comunicaciones expeditas contribuyeron a definir una jerarquía de espacios y mediaciones, con los líderes agraristas xichulenses convertidos en un punto de apoyo importante para el control del interior serrano.

${ }^{24}$ ARAN, Expediente Ejidal General, Expediente de Dotación, Ejido Mangas Cuatas, carta de abril de 1940. De acuerdo con Tarquín para esos años Luis Ferro echó mano de excristeros y antiagraristas colocándolos en posiciones claves dentro del Banco Ejidal y de las delegaciones agrarias (1988, 14-15).

${ }^{25}$ Ferro se hizo de un rancho en San Miguel de Allende, "unas 100 hectáreas al lado del río Laja [entonces siempre con agua], le hizo un tajo y con una bomba a regar" cultivos de frijol y maíz que comercializaba posteriormente en Celaya e Irapuato. L.F.S., San José Iturbide, entrevista, 25/II/08.

${ }^{26}$ Una de las relaciones políticas más significativas de Tarquín fue con la Misión de Chichimecas. Los chichimecas lograron una importante dotación de tierras en 1928 y una ampliación en 1936, con apoyos y financiamientos estatales, y con tramitación para pozos de agua obtenidos hasta finales de la década de 1960. Tarquín contribuyó directamente en varios de esos procesos, en cambio tuvo una relación incidental con la población otomí de los municipios serranos. Cabe señalar que chichimecas y otomíes -al menos los de las comunidades más emblemáticas de la Sierra- tuvieron una posición diferenciada con respecto al reparto agrario posrevolucionario, ya que las leyes liberales del siglo XIX también los afectaron de manera desigual. Los chichimecas de la Misión se sumaron resueltamente al agrarismo manteniendo su fe religiosa a distancia de los dictados de la Iglesia católica, en contraste con muchos de los asentamientos mestizos colindantes, de claro perfil antiagrarista, procristero y proeclesial. Por su parte los otomíes del municipio de Tierra Blanca evitaron las tensiones del agrarismo ya que pudieron comprar sus tierras desde la década de 1870 . Sus simpatías cristeras estuvieron más relacionadas con lógicas internas de convivencia y menos con su oposición al proyecto agrarista estatal (Uzeta 2004). 
Por otra parte, el fin del reparto agrario verificado en la década de 1950 en Guanajuato, relajó eventualmente los enfrentamientos entre ambos caciques regionales. Es posible que la distensión estuviera relacionada con los mismos vaivenes políticos que habían favorecido a uno u otro desde 1920: la década de 1940 había resultado muy conflictiva para los grupos políticos de la entidad, pues se sucedieron varios gobernadores a la caída de Ernesto Hidalgo (1943-1946) por su presunta responsabilidad en una masacre de sinarquistas en la ciudad de León. La estabilidad sólo se logró con un amigo cercano del presidente Alemán en el gobierno de la entidad, el exprocurador general José Aguilar y Maya, quien ganó el apoyo de rojos a través del repatriado Melchor Ortega, y de los verdes a través de Enrique Fernández Martínez (Rionda 1997a, 41).

No obstante fue en ese periodo cuando se verificó una fuerte movilización campesina ante las elecciones presidenciales de 1952, en las cuales Ruiz Cortínez venció a Miguel Henríquez Guzmán, candidato opositor. Desde un año antes el gobernador Aguilar y Maya había declarado que "ya no existen tierras para dotación o ampliación por estar repartidas casi en su totalidad [...]" y que lo conducente en materia agraria eran trabajos de deslinde y amojonamiento en espacios ya repartidos, señalamiento que reiteraría en varias ocasiones (Guanajuato 1991, 848). Esta decisión de estado-no sólo de gobierno- abonó a favor de Henríquez Guzmán, quien logró un amplio apoyo campesino a través de la Federación de Partidos del Pueblo Mexicano, con una filial en la entidad, el Partido del Pueblo Guanajuatense (Rionda 1997a, 110). Aunque dirigentes verdes como el exgobernador Arroyo Ch se deslindaron de esta postulación, Luis y Lauro Ferro tuvieron una posición dubitativa ante Henríquez en San Miguel de Allende y en San José Iturbide. ${ }^{27}$ Es posible también que Tarquín y los jefes locales simpatizaran en su fuero interno con un candidato proagrarista como Henriquez. En todo caso la indefinición de los Ferro no encontró eco en Atarjea, en donde el PRI arrasó y el cacique Guadalupe Hernández alcanzó la

${ }^{27}$ Rionda señala que agentes del gobierno guanajuatense los identificaron en un mitin a favor del henriquismo en Querétaro (1997a, 124). 
alcaldía. El regreso de Luis Ferro al primer plano político se dio justamente con la diputación federal, para lo cual debió requerir todo el apoyo posible, incluso el de un agrarismo oficialista menguado representado por la figura burocratizada de Tarquín.

De acuerdo con el hijo de Ferro, su padre y Tarquín superaron sus antiguas diferencias llegando incluso a ser amigos, de hecho este último fungió como fogoso orador en la campaña de aquél, entonces flamante candidato a la cámara de diputados en 1956-1957. Y aunque Tarquín no corrigió sus memorias, en las cuales Ferro aparece retratado de manera tan desfavorable, este último parece haber influido para que su otrora contrincante mantuviera su posición en la Liga de Comunidades Agrarias y en la Procuraduría del ramo durante el gobierno de Torres Landa en la entidad (1961-1967).

La efectividad de estas mediaciones se debilitó en la década de 1970 sin que Ferro (fallecido en los setenta) o Tarquín (fallecido en 1983) lograran ser relevados por algunos de sus hijos pese a sus respectivos desempeńos políticos. Todavía en 1976, Tarquín tuvo un papel en la gira proselitista del candidato presidencial López Portillo por la Sierra. Pero la fuerza menguante de estos liderazgos también se fue generando desde abajo, desde la insatisfacción por las promesas incumplidas, por la prolongación de las disputas entre linderos ejidales, y frente a la diversificación social, el relevo generacional y el surgimiento de nuevos grupos con intereses económicos y políticos distintos a los agrarios. Asuntos fundamentales que produjeron otros parentescos y nuevas y más acotadas mediaciones que habrá que abordar en otra parte.

\section{Comentarios finales}

De acuerdo con Alan Knight, el Estado surgido de la revolución estuvo "tan comprometido con el desarrollo y la centralización como su predecesor porfiriano, pero [...] empleó medios más eficaces para estos fines" $(1995,35)$. En la Sierra ejidos e intermediarios fueron esos medios; su eficiencia y legitimidad se alimentaba lo mismo de demandas y luchas previas que prefiguraban identidades sociales agraristas, que de valores asociados con una cultura política de corte patriarcal. 
Como organización perfilada para el control y la representación campesina el ejido requería de enlaces con niveles superiores de poder político. En contextos de violencia social, prácticamente al calor de enfrentamientos armados sucesivos y a veces simultáneos con propietarios, con simpatizantes de distintos caudillos (Gasca, Cedillo), con fuerzas cristeras, con bandoleros y con un etcétera más o menos largo, tales enlaces fueron urdidos como relaciones personales y tradicionales de parentela, de amistad y lealtad entre, digamos, líderes de nivel medio perfilados a la construcción de instituciones y los caciques locales. Y pese a que los intermediarios regionales estaban confrontados porque entendían el agrarismo de diferente manera y a través de vínculos políticos enfrentados, supieron capitalizar demandas y valores locales moviéndose con sagacidad al menos en tres ámbitos: el partido y sus confederaciones, las cámaras de diputados (federal y de la entidad), y los municipios económica y políticamente más importantes de la Sierra. La conformación del Estado posrevolucionario (de la CNC, del PRI, de las agencias agrarias) fue posible gracias a sus relaciones y a su habilidad para mantenerlas.

Por otra parte es cierto que por lo general "los líderes campesinos no superan los límites de sus municipios, pero este liderazgo se fundamenta en el control de la base campesina a través del éxito de la intermediación burocrática” (Martínez Saldaña 1991, 336). En los municipios de Atarjea y Xichú, y más ampliamente en la Sierra Gorda guanajuatense, el éxito de la intermediación se verificaba precisamente enlazando y jerarquizando varios municipios y manteniéndolos así incluso a pesar de las tensiones derivadas del cambio en el acento agrarista del régimen y del reacomodo de los liderazgos locales y regionales como parte de la política partidista (por no hablar de los problemas generados por la enredada tramitología ejidal y la burocracia agraria). La longevidad de los intermediarios o caciques regionales dependió de eso, la de los locales lo hizo de vínculos de parentesco y de la actualización de valores que permitieron a los ejidatarios identificar a los jefes de diversos niveles como autoridades interesadas en mantener relaciones de intercambio. Relaciones mutuamente fructíferas aunque, desde luego, desiguales. 


\section{BibliografíA}

Abrams, Philip, "Notes on the Difficulty of Studying the State", Journal of Historical Sociology, núm. 1, vol. I, 1988.

BARTra, Roger, "Campesinado y poder político en México", en Roger Bartra, E. Boege, P. Calvo et al., Caciquismo y poder politico en el México rural, México, IIs/unam, Siglo XXI, 1976.

Blanco, Mónica, Alma Parra y Ethelia Ruiz Medrano, Breve historia de Guanajuato, México, FCE, El Colegio de México, 2000.

De la Peña, Guillermo, "Poder local poder regional: perspectivas socioantropológicas”, Jorge Pádua y Alain Vanneph, compiladores, Poder local poder regional, México, El Colegio de México, CEMCA, 1988.

Falcón, Romana, Revolución y caciquismo en San Luis Potosí 19101938, México, El Colegio de México, 1984.

González, Pedro, Geografía Local del Estado de Guanajuato, Guanajuato, Tipografía de la Escuela Industrial Militar, 1904

Guanajuato en la voz de sus gobernadores, Compilación de Informes de Gobierno 1917- 1991, Tomo II, Guanajuato, Gobierno del Estado de Guanajuato, 1991.

Guerrero TArquín, Alfredo, Memorias de un agrarista, 2 tomos, México, SEP/INAH, 1987

, Reminiscencias de un viaje a través de la Sierra Gorda, México INAH, 1988.

Jones, Gareth A., "Dismantling the Ejido: A Lesson in Controlled Pluralism", Rob Aitken, Nikki Craske, Gareth A. Jones and David E. Stanfield, eds., Dismantling the Mexican State?, Nueva York, St. Martin's Press, 1996.

Jospen, Gilbert M., "El caciquismo y la revolución: Carrillo Puerte en Yucatán", en David Brading, comp., Caudillos y campesinos en la Revolución Mexicana, México, FCE, 1995.

KNIGHT, Alan, "Caudillos y campesinos en el México revolucionario, 1910- 1917", en David Brading, comp., Caudillos y campesinos en la Revolución Mexicana, México, FCE, 1995.

, "Caciquismo in Twentieth-century Mexico", en Alan 
Knight y Wil Pansters, Caciquismo in Twenthieth-Century Mexico, Londres, Institute for the Study of the Americas, 2005

Martínez Saldaña, Tomás, "Agricultura y estado en México. Siglo xx", Teresa Rojas, coord., La agricultura en tierras mexicanas desde sus origenes hasta nuestros días, CNCA/ Grijalbo, 1991.

Muñuzuri, Eduardo, De Casas Viejas a Casas Nuevas, Edición Municipal gratuita, San José Iturbide, 1997.

Ortner, Sherry B, Anthropology and Social Theory. Culture, Power and the Acting Subject, Durham, Duke University Press, 2006.

Rionda Ramírez, Luis Miguel, Enrique Fernández Martínez, un gobernador de la vorágine. El cardenismo y la ruptura generacional revolucionaria, Guanajuato Congreso del Estado de Guanajuato, 1996.

, José Aguilar y maya. Transición política e institucionalidad en Guanajuato, LVI Legislatura, H. Congreso del Estado de Guanajuato, 1997a.

, Cultura politica y elecciones en Guanajuato, Cuadernos del CICSUG, núm. 9, $1997 \mathrm{~b}$.

Sepúlveda, Manola, Politicas agrarias y luchas sociales: San Diego de la Unión, Guanajuato 1900-2000, Procuraduría Agraria/ INAH, 2000.

, "Paradojas de la historia ejidal: El Llanito, Dolores Hidalgo, Guanajuato, 1930-1960”, Cuicuilco, nueva época, núm. 31, vol. 11, 2004.

, "Surgimiento y derrota de un terrateniente ejidal: Río Laja, Dolores Hidalgo, 1930-1970”, Revista de los Tribunales Agrarios, segunda época, núm. 35, año II, 2005.

STERN, Steve J., La historia secreta del género. Mujeres, hombres y poder en México en las postrimerias del periodo colonial, México, FCE, 1999.

UzETA, Jorge, "Ejidatarios y chichimecas: identidad india a través de la formación de un ejido guanajuatense”, Patricia Moctezuma, Juan Carlos Ruiz, Jorge Uzeta, coords., Guanajuato: aportaciones recientes para su estudio, San Luis Potosí, El Colegio de San LuisUniversidad de Guanajuato, 2004.

, "El bien común y el bien particular en el Mineral de Atar- 
jea, Guanajuato (1871-1891)”, Relaciones Estudios de Historia y Sociedad, núm. 102, vol. XXVI, Zamora, El Colegio de Michoacán, 2005.

Valencia García, Guadalupe, Guanajuato. Sociedad, economía, política, cultura, Biblioteca de las entidades federativas, México, CIICYH/ UNAM, 1998.

Wolf, Eric R., "Aspects of Group Relations in a Complex Society: Mexico", Theodor Shanin, ed., Peasants and peasants societies, Londres, Penguin Books, 1971.

, "Relaciones de parentesco, de amistad y de patronazgo en las sociedades complejas", Michael Banton, compilador, Antropología social de las sociedades complejas, Madrid, Alianza Universidad, 1990.

Zárate, José Eduardo, "Caciques and Leaders in the Era of Democracy”, en Alan Knight y Wil Pansters, Caciquismo in Twenthieth-Century Mexico, Mexico, Londres, Institute for the Study of the Americas, 2005.

FeCHA DE RECEPCión DEL ARTículo: 1 de julio de 2010

FECHA DE ACEPTACIÓN Y RECEPCiÓN DE LA VERSIÓN FINAL: 5 de diciembre de 2010 